\title{
Tratamentos Pré-Germinativos na Emergência e Desenvolvimento Inicial de Plântulas de Graviola
}

\section{Pre-Germinative Treatments on the Emergency and Initial Development of Soursop Seedlings}

\author{
Marcus Vinicius Sandoval Paixão*a; Andrieli Ferrari Mônicoa; Rafaela Barreto Cazaroto Grobérioa; Gustavo Miranda \\ Cremoninia; Hélio Pena de Faria Junior ${ }^{\mathrm{a}}$; Almy Junior Carvalho de Cordeiro ${ }^{\mathrm{b}}$
}

\author{
anstituto Federal de Ciência e Tecnologia do Espírito Santo, Campus Santa Teresa. ES, Brasil.

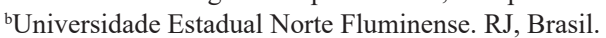 \\ *E-mail: mvspaixao@gmail.com
}

\begin{abstract}
Resumo
A graviola, Annona muricata L., produz sementes que podem apresentar dormência ocasionada pela impermeabilidade do tegumento à água, necessitando assim de métodos para superação desta. Objetivou-se avaliar o efeito de tratamentos pré-germinativos na emergência e desenvolvimento inicial de plântulas de graviola. O delineamento experimental utilizado foi em blocos ao acaso, com 13 tratamentos e quatro repetições, sendo cada unidade experimental composta de 50 sementes. As sementes foram submetidas aos tratamentos com imersão por 30 minutos, os quais foram: água $\left(26^{\circ} \mathrm{C}\right.$ testemunha), solução de giberelina a $1.000,2.000,3.000$ e $4.000 \mathrm{mg}$. $\mathrm{L}^{-1}$, água com gelo em ponto de fusão $\left(0{ }^{\circ} \mathrm{C}\right)$, congelador por 6 horas $\left(-10^{\circ} \mathrm{C}\right)$, geladeira por 24 horas $\left(10^{\circ} \mathrm{C}\right)$, água em ponto de ebulição $\left(100{ }^{\circ} \mathrm{C}\right)$, solução de $\mathrm{NaCl} 9 \mathrm{~g} . \mathrm{L}^{-1}$, solução de $\mathrm{KCl} 5$ g.L. $\mathrm{L}^{-1}$, água de coco e suco de laranja. A semeadura ocorreu em tubetes $280 \mathrm{~mL}$ contendo substrato composto por solo+esterco bovino. Trinta dias após a semeadura (DAS) avaliou-se a porcentagem, índice de velocidade e tempo médio de emergência das plântulas. Sessenta dias após a semeadura foram avaliados: número de folhas; altura da planta; diâmetro do coleto; comprimento da raiz; massa verde foliar; massa seca foliar; massa verde e massa seca da raiz. O tratamento com giberelina de $4.000 \mathrm{mg} . \mathrm{L}^{-1}$ de $\mathrm{GA}_{3}$ foi o tratamento mais eficiente para induzir a emergência e desenvolvimento inicial de plântulas de graviola.
\end{abstract}

Palavras-chave: Annona muricata. Giberelina. Propagação.

\begin{abstract}
Soursop, Annona muricata L., produces seeds that may present dormancy caused by the impermeability of the integument to water, thus requiring methods to overcome it. The objective was to evaluate the effect of pre-germinative treatments on the emergence and initial development of soursop seedlings. The experimental design used was in randomized blocks, with 13 treatments and four replications, each experimental unit consisting of 50 seeds. The seeds were submitted to immersion treatments for 30 minutes, which were: water $\left(26^{\circ} \mathrm{C}\right.$ control), 1.000 gibberellin solution, 2.000, 3.000 e $4.000 \mathrm{mg} \cdot \mathrm{L}^{-1}$, water with ice at melting point $\left(0^{\circ} \mathrm{C}\right)$, freezer for 6 hours $\left(-10^{\circ} \mathrm{C}\right)$, refrigerator for 24 hours $\left(10^{\circ} \mathrm{C}\right)$, boiling water $\left(100^{\circ} \mathrm{C}\right), \mathrm{NaCl} 9 \mathrm{~g} \cdot \mathrm{L}^{-1}$ solution, $\mathrm{KCl} 5 \mathrm{~g} \cdot \mathrm{L}^{-1}$ solution, coconut water and orange juice. Sowing took place in $280 \mathrm{~mL}$ tubes containing substrate composed of soil + bovine manure. Thirty days after sowing (DAS), the percentage, speed index and mean seedling emergence time were evaluated. Sixty days after sowing the following items were evaluated: number of leaves; plant height; collar diameter; root length; leaf green mass; leaf dry mass; green mass and dry mass of the root. The treatment with gibberellin of $4.000 \mathrm{mg}^{-L^{-1}}$ of GA ${ }_{3}$ was the most efficient treatment to induce the emergence and initial development of soursop seedlings.
\end{abstract}

Keywords: Annona muricate. Gibberellin. Propagation.

\section{Introdução}

Annona muricata L. é uma espécie frutífera exótica da família Annonaceae e faz parte de um grupo de plantas que vem se destacando em várias regiões do mundo, pelo fato de produzirem frutos de grande importância comercial (LEMOS, 2014). Embora seja explorada comercialmente em diversas regiões do mundo, apenas alguns países apresentamse como grandes produtores, sendo os países produtores que mais se destacam no mercado das anonáceas: Austrália, Chile, Espanha, Estados Unidos, Nova Zelândia e Israel, para cherimólia; México, Brasil, Venezuela e Costa Rica, para graviola; e Tailândia, Filipinas, Brasil, Cuba e Índia (SÃO JOSE et al., 2014).

As anonáceas são as plantas da família Annonaceae, constituída por cerca de 120 gêneros e em torno de 2.300 espécies. No Brasil, estão registrados 29 gêneros, dentro dos quais cerca de 260 espécies (BRAGA SOBRINHO, 2014). Em diversos locais do mundo encontramos frutos comestíveis cultivados em pomares comerciais ou coletados de forma extrativista de espécies da família Annonaceae, sendo a maioria nas zonas tropicais do novo e velho mundo, e poucos gêneros presentes em zonas de clima temperado (SÃO JOSE et al., 2014).

O interesse por esta frutífera vem aumentando gradativamente no Brasil devido à alta aceitação no mercado, por apresentar grandes perspectivas para exportação, além da crescente demanda pelas agroindústrias de fabricação de polpas, néctares, sucos, sorvetes e geleias (OLIVEIRA et al., 
2009). A graviola é utilizada para obtenção de polpa, suco, néctar, entre outros (WATANABE et al., 2014) possuindo diversas propriedades nutricionais e até medicinais, ganhando destaque na fruticultura brasileira (GAJALAKSHMI et al., 2012), porém, mesmo considerada fruteira de baixa expressão em relação as principais frutíferas produzidas no Brasil, as indústrias de suco estão proporcionando uma promissora fruta para exportação (SAMARAO et al., 2011)

A graviola aparece como a segunda anonácea em área cultivada e em produção no Brasil, ficando somente atrás da pinheira (Annona squamosa) (LEMOS, 2014). No Brasil, além da graviola (A. muricata L.) e pinha (A. squamosa L.), encontramos também os cultivos de atemoia e cherimólia (SÃO JOSE, 2014), sendo os Estados da Bahia e Alagoas os maiores produtores. (BRAGA SOBRINHO et al. 2012).

A propagação da graviola pode ser realizada de forma sexuada ou assexuadamente por enxertia. A propagação por sementes, em anonáceas, produz plantas mais vigorosas, com sistema radicular abundante e profundo, maior longevidade, além de proporcionarem a obtenção de novas variedades e formação de bancos de germoplasma (KITAMURA; LEMOS, 2004).

Apesar de apresentar grande referencial econômico, as sementes da graviola apresentam substâncias inibidoras da germinação, promovendo a dormência, além de terem um tegumento resistente e impermeável, o que proporciona antagonismo à germinação rápida e uniforme (STENZEL et al., 2003). Devido a essa limitação no processo de germinação torna-se necessário recorrer à utilização de alguns métodos de superação de dormência para favorecer a germinação das sementes dessa espécie.

As sementes da família Annonaceae são ortodoxas, ou seja, toleram o armazenamento por tempo prolongado, todavia, apresentam baixa resistência ao ataque de bactérias e fungos, apresentam germinação lenta e desuniforme, este fato ocorre porque o embrião é pouco desenvolvido, necessitando primeiramente, constituir seus órgãos para em seguida, ocorrer à germinação (JOSE et al., 2007).

Além de fatores fisiológicos que impedem a germinação das sementes da família das anonáceas, ainda existe a dormência física. Dentre os fatores físicos, a dormência está relacionada com a densidade do tegumento, que causa impermeabilidade da casca, dificultando a entrada de ar e trocas gasosas, por apresentar uma capa lenhosa que retarda o processo germinativo das sementes, diante disto, algumas espécies podem demorar até 6 meses para germinar (MANICA, 1997).

A pesquisa foi realizada com o objetivo de avaliar o efeito de tratamentos pré-germinativos na emergência e desenvolvimento inicial de plântulas de graviola (Annona muricata L.).

\section{Material e Métodos}

O experimento foi conduzido no Viveiro de Produção de Mudas do Setor de Viveiricultura, construído com tela de poliolefina com $50 \%$ de sombreamento, pertencente ao Instituto Federal do Espírito Santo (IFES-Campus Santa Teresa), no período de agosto a outubro de 2019, que localizase na meso região central Espírito-Santense, no município de Santa Teresa-ES, possuindo coordenadas geográficas de 1956'12'S e 40³5'28'”, com altitude de $155 \mathrm{~m}$. O clima da região caracteriza-se como Cwa, mesotérmico, com estação seca no inverno e forte pluviosidade no verão (Classificação de Köppen) (ALVARES et al., 2013), com precipitação anual média de $1.404,2 \mathrm{~mm}$ e temperatura média anual de $19,9{ }^{\circ} \mathrm{C}$, máxima de $32,8^{\circ} \mathrm{C}$ e mínima de $10,6^{\circ} \mathrm{C}$ (INCAPER, 2011).

Foram utilizadas sementes de graviola da cultivar 'Morada', de frutos recém colhidos na região de São Roque do Canaã, ES, com extração manual das sementes. As sementes foram submetidas aos tratamentos de imersão por 30 minutos, sendo eles: água pura $26^{\circ} \mathrm{C}$ (testemunha); solução de giberelina a 1.000, 2.000, 3.000 e $4.000 \mathrm{mg.L}{ }^{-1}$, água com gelo em ponto de fusão $\left(0{ }^{\circ} \mathrm{C}\right)$, água em ponto de ebulição $\left(100^{\circ} \mathrm{C}\right)$, congelador por $6 \mathrm{~h}\left(-10^{\circ} \mathrm{C}\right)$, geladeira $24 \mathrm{~h}\left(10^{\circ} \mathrm{C}\right)$, solução de $\mathrm{NaCl} 9$ g.L ${ }^{-1}$, solução de $\mathrm{KCl} 5$ g.L $\mathrm{L}^{-1}$, água de coco (Cocos nucifera) e suco de laranja (Citrus spp.).

$\mathrm{O}$ experimento foi conduzido em delineamento experimental de blocos casualizados (DBC), com 13 tratamentos e quatro repetições, com cada unidade experimental composta de 50 sementes. A semeadura foi realizada em tubetes com capacidade de $280 \mathrm{ml}$, sendo escolhido para substrato a mistura padrão utilizada nos viveiros, solo+esterco bovino na proporção $(3: 1)$.

Após a semeadura, diariamente durante trinta dias foram coletados o número de plantas emergidas para os dados de emergência (E), índice de velocidade de emergência (IVE) e tempo médio de emergência (TME). Sessenta dias após a semeadura (DAS), coletou-se dez plantas de cada repetição em cada tratamento, escolhidas aleatoriamente, na qual foram avaliados: altura da planta (AP), número de folhas (NF), diâmetro do coleto (DC), comprimento da raiz (CR), massa verde foliar (MVF), massa seca foliar (MSF), massa verde da raiz (MVR), massa seca da raiz (MSR). Para obtenção da massa seca das folhas e da raiz, as dez plantas coletadas e avaliadas foram acondicionadas em sacos de papel, submetidas a secagem em estufa a $70^{\circ} \mathrm{C}$ durante 72 horas, para posterior pesagem em balança analítica.

Os dados experimentais foram submetidos à análise de variância pelo teste $\mathrm{F}$, atendendo as pressuposições do modelo pelo teste de Shapiro-Wilk para verificação da normalidade e as médias dos tratamentos foram comparadas pelo teste Tukey em nível de $5 \%$ de probabilidade.

\section{Resultados e Discussão}

Para a porcentagem de emergência das plântulas, e de 
acordo com os tratamentos das sementes apresentados no Quadro 1, observa-se que esta variável apresentou diferença estatística entre os métodos de superação de dormência avaliados. A porcentagem de emergência para o tratamento com giberelina $4.000 \mathrm{mg} . \mathrm{L}^{-1}$ apresentou o maior valor absoluto, porém se diferença estatística para os tratamentos Geladeira $\left(10{ }^{\circ} \mathrm{C}\right)$ e $\mathrm{NaCl} 9$ g.L $\mathrm{L}^{-1}$ e estatisticamente superior em comparação aos demais tratamentos avaliados, com 94\% de emergência, sendo que a testemunha obteve $80 \%$.

Quadro 1 - Emergência de plântulas de graviola provenientes de sementes submetidas a diferentes tratamentos pré germinativos

\begin{tabular}{|l|c|c|c|}
\hline Tratamentos & E (\%) & IVE & TME \\
\hline Testemunha & $80 \mathrm{c}$ & $1,670 \mathrm{abc}$ & $12,352 \mathrm{a}$ \\
\hline Geladeira $\left(10^{\circ} \mathrm{C}\right)$ & $89 \mathrm{ab}$ & $1,894 \mathrm{ab}$ & $12,215 \mathrm{a}$ \\
\hline Água com gelo $\left(0^{\circ} \mathrm{C}\right)$ & $78 \mathrm{c}$ & $1,6075 \mathrm{bc}$ & $12,877 \mathrm{a}$ \\
\hline Congelador $\left(-10^{\circ} \mathrm{C}\right)$ & $59 \mathrm{~d}$ & $1,217 \mathrm{c}$ & $12,762 \mathrm{a}$ \\
\hline $\mathrm{GA}_{3} 1.000 \mathrm{mg} . \mathrm{L}^{-1}$ & $82 \mathrm{c}$ & $1,801 \mathrm{ab}$ & $11,915 \mathrm{a}$ \\
\hline $\mathrm{GA}_{3} 2.000 \mathrm{mg} . \mathrm{L}^{-1}$ & $85 \mathrm{bc}$ & $1,888 \mathrm{ab}$ & $11,643 \mathrm{a}$ \\
\hline $\mathrm{GA}_{3} 3.000 \mathrm{mg}^{-\mathrm{L}^{-1}}$ & $88 \mathrm{~b}$ & $2,020 \mathrm{ab}$ & $11,266 \mathrm{a}$ \\
\hline $\mathrm{GA}_{3} 4.000 \mathrm{mg} . \mathrm{L}^{-1}$ & $94 \mathrm{a}$ & $2,156 \mathrm{a}$ & $11,198 \mathrm{a}$ \\
\hline Água de coco & $86 \mathrm{bc}$ & $1,776 \mathrm{ab}$ & $12,907 \mathrm{a}$ \\
\hline Suco de laranja & $87 \mathrm{bc}$ & $1,826 \mathrm{ab}$ & $12,625 \mathrm{a}$ \\
\hline NaCl 9 g.L $\mathrm{L}^{-1}$ & $90 \mathrm{ab}$ & $1,854 \mathrm{ab}$ & $12,722 \mathrm{a}$ \\
\hline $\mathrm{KCl} 5$ g.L $\mathrm{L}^{-1}$ & $81 \mathrm{c}$ & $1,744 \mathrm{ab}$ & $12,113 \mathrm{a}$ \\
\hline Água a $100^{\circ} \mathrm{C}$ & 0 & 0 & 0 \\
\hline $\mathrm{CV}(\%)$ & 10,09 & 11,75 & 7,20 \\
\hline
\end{tabular}

Médias seguidas por uma mesma letra nas colunas não diferem estatisticamente pelo teste de Tukey a $5 \%$ de probabilidade. $\mathrm{E}=$ Porcentagem de emergência (\%); IVE= Índice de velocidade de emergência; TME $=$ Tempo médio de emergência. $\mathrm{CV}=$ Coeficiente de variação.

Fonte: Dados da pesquisa.

O tratamento congelador por 6 horas $\left(-10^{\circ} \mathrm{C}\right)$ mostrouse menos eficiente na emergência que os outros tratamentos, com 59\% de emergência (Quadro 1). Essa menor taxa de emergência pode ser explicada, pelo fato da gravioleira ser uma planta tropical, que não necessita de vernalização para que suas sementes germinem, podendo ser até mesmo prejudicada por este processo, além do fato, da baixa temperatura ter levado à cristalização do tecido celular, ou até mesmo a morte, resultando em baixa emergência.

No índice de velocidade de emergência (IVE), apenas os tratamentos Água com gelo $\left(0^{\circ} \mathrm{C}\right)$ e Congelador $\left(-10^{\circ} \mathrm{C}\right)$ apresentaram diferença estatística para os outros tratamentos, sendo que o tratamento com giberelina $4.000 \mathrm{mg} . \mathrm{L}^{-1}$ apresentou o maior valor absoluto (Tabela 1). Provavelmente a maior velocidade de emergência das sementes tratadas com soluções contendo giberelina, pode estar relacionada ao efeito de enfraquecimento da camada do endosperma que envolve o embrião, desenvolvendo o seu crescimento de forma mais adequada visto que o envoltório não implica em uma barreira física, atuando apenas como proteção da semente.

Em relação ao tempo médio de emergência (TME), não foi observado diferença estatística entre os tratamentos utilizados na pesquisa (Quadro 1).
O tratamento térmico utilizando água em ponto de ebulição $\left(100^{\circ} \mathrm{C}\right)$ não promoveu a germinação das sementes, resultando na morte do embrião.

Pinto (1976), trabalhando com sementes de graviola (Annona muricata L.), obteve $82 \%$ de germinação, com o uso de $300 \mathrm{mg} . \mathrm{L}^{-1}$ de ácido giberélico, enquanto que, a testemunha apresentou $75 \%$, indicando que a giberelina é eficiente para emergência das plântulas desta espécie. Corroborando com esta pesquisa, Pimenta et al. (2019) pesquisando o efeito da giberelina na superação de dormência de araticunzeiro, concluiu que sementes de araticunzeiro possuem dormência fisiológica, podendo ser superada pela aplicação de GA3, promovendo maior porcentagem de germinação e maior velocidade de germinação de sementes de araticunzeiro.

Stenzel et al. (2003) trabalhando com superação de dormência de sementes de atemóia e de cherimoia, concluíram que o uso do ácido giberélico a 50 e $100 \mathrm{mg} . \mathrm{L}^{-1}$ proporcionou valores superiores de porcentagem de germinação e índice de velocidade de germinação em comparação às sementes não tratadas, independente do material genético utilizado no estudo. Menegazzo et al. (2012), estudando o efeito do ácido giberélico, ácido sulfúrico, imersão em água a $30^{\circ} \mathrm{C}$ e 60 ${ }^{\circ} \mathrm{C}$, e escarificação com lixa em pinha, relatam que a maior porcentagem de germinação e melhor desenvolvimento de plântulas foi obtido quando utilizou-se o tratamento com ácido giberélico.

O ácido giberélico atua na expressão gênica sinalizando a síntese de diversas enzimas hidrolíticas, tais como $\alpha$ e $\beta$ amilase (TAIZ; ZEIGER, 2013). Entretanto, sementes em estado de dormência apresentam baixas concentrações de $\alpha$ amilase (VIEIRA et al., 2008), sendo necessário que sejam sintetizadas novamente durante a fase da germinação. Portanto, para que haja a indução da síntese dessas enzimas é preciso que as giberelinas estejam disponíveis às sementes, que atuarão como ativador de fatores de transcrição, conduzindo a expressão gênica das enzimas amilolíticas. Essas enzimas, por sua vez, quando sintetizadas, serão responsáveis por hidrolisar substâncias do tecido de reserva da semente, que posteriormente serão assimiladas, formando aminoácidos, açúcares e demais substâncias destinadas ao eixo embrionário, estimulando o seu crescimento e alongamento, culminando na protrusão da radícula. Além disso, essas enzimas também atuam na modificação da parede celular, facilitando a ruptura do tegumento (PENG; HARBERD, 2002), fazendo com que a germinação ocorra de maneira mais rápida e uniforme, resultando, portanto, não só em maior percentagem de germinação, como também, incremento na velocidade desta.

No Quadro 2, observa-se que para a Altura de plântulas houve diferença estatística entre os tratamentos, sendo que, a imersão em giberelina $4.000 \mathrm{mg} . \mathrm{L}^{-1}$ apresentou maior valor de altura de plântulas, assim como os tratamentos $\mathrm{GA}_{3}$ $3.000 \mathrm{mg} . \mathrm{L}^{-1}$, suco de laranja e testemunha que foram iguais estatisticamente ao tratamento giberelina $4.000 \mathrm{mg} \cdot \mathrm{L}^{-1}$, e este último superior numericamente aos demais tratamentos. 
Quadro 2 - Desenvolvimento de plântulas de graviola provenientes de sementes submetidas a diferentes tratamentos pré germinativos

\begin{tabular}{|l|c|c|c|c|}
\hline \multicolumn{1}{|c|}{ Tratamento } & AP & NF & DC & CR \\
\hline Testemunha & $14,14 \mathrm{abc}$ & $4,6 \mathrm{ab}$ & $3,04 \mathrm{a}$ & $11,27 \mathrm{c}$ \\
\hline Geladeira $\left(10{ }^{\circ} \mathrm{C}\right)$ & $13,28 \mathrm{c}$ & $4,5 \mathrm{ab}$ & $3,25 \mathrm{a}$ & $11,87 \mathrm{abc}$ \\
\hline Água com gelo $\left(0^{\circ} \mathrm{C}\right)$ & $13,31 \mathrm{c}$ & $4,1 \mathrm{~b}$ & $3,06 \mathrm{a}$ & $12,15 \mathrm{ab}$ \\
\hline Congelador $\left(-10^{\circ} \mathrm{C}\right)$ & $13,35 \mathrm{c}$ & $4,2 \mathrm{~b}$ & $3,00 \mathrm{a}$ & $11,66 \mathrm{bc}$ \\
\hline $\mathrm{GA} 31000 \mathrm{mg} \cdot \mathrm{L}^{-1}$ & $13,31 \mathrm{c}$ & $4,7 \mathrm{ab}$ & $3,05 \mathrm{a}$ & $12,09 \mathrm{abc}$ \\
\hline $\mathrm{GA} 32000 \mathrm{mg} \cdot \mathrm{L}^{-1}$ & $13,80 \mathrm{bc}$ & $4,7 \mathrm{ab}$ & $3,06 \mathrm{a}$ & $12,56 \mathrm{a}$ \\
\hline $\mathrm{GA} 33000 \mathrm{mg} \cdot \mathrm{L}^{-1}$ & $14,62 \mathrm{ab}$ & $4,7 \mathrm{ab}$ & $3,00 \mathrm{a}$ & $12,19 \mathrm{ab}$ \\
\hline $\mathrm{GA} 34000 \mathrm{mg} \cdot \mathrm{L}^{-1}$ & $15,02 \mathrm{a}$ & $5,1 \mathrm{a}$ & $3,08 \mathrm{a}$ & $11,95 \mathrm{abc}$ \\
\hline Água de coco & $14,41 \mathrm{bc}$ & $4,3 \mathrm{~b}$ & $2,94 \mathrm{a}$ & $11,85 \mathrm{abc}$ \\
\hline Suco laranja & $14,16 \mathrm{abc}$ & $4,4 \mathrm{ab}$ & $2,97 \mathrm{a}$ & $11,68 \mathrm{bc}$ \\
\hline NaCl $9 \mathrm{~g} \cdot \mathrm{L}^{-1}$ & $13,11 \mathrm{c}$ & $4,2 \mathrm{~b}$ & $3,13 \mathrm{a}$ & $11,95 \mathrm{abc}$ \\
\hline $\mathrm{KCl} 5 \mathrm{~g} \cdot \mathrm{L}^{-1}$ & $13,31 \mathrm{c}$ & $4,3 \mathrm{~b}$ & $2,94 \mathrm{a}$ & $11,97 \mathrm{abc}$ \\
\hline Água a $100{ }^{\circ} \mathrm{C}$ & 0 & 0 & 0 & 0 \\
\hline $\mathrm{CV}(\%)$ & 8,47 & 13,13 & 11,05 & 7,01 \\
\hline
\end{tabular}

Médias seguidas das mesmas letras nas colunas são estatisticamente iguais pelo teste de Tukey em $5 \%$ de probabilidade. $\mathrm{AP}=$ altura da planta $(\mathrm{cm}) ; \mathrm{NF}=$ número de folhas; $\mathrm{DC}=$ diâmetro do coleto $(\mathrm{mm}) ; \mathrm{CR}=$ comprimento da raiz $(\mathrm{cm}) ; \mathrm{CV}=$ coeficiente de variação.

Fonte: Dados da pesquisa

A variável número de folhas apresentou maior valor nos tratamentos com giberelina 4.000, 3.000, 2.000 e 1.000 mg.L. $\mathrm{L}^{-1}$, testemunha, geladeira e suco de laranja, sendo estes estatisticamente iguais e diferindo-se em comparação aos demais tratamentos (Quadro 2).

Não houve diferença em relação ao diâmetro do coleto para os tratamentos estudados, já para a variável comprimento da raiz, apenas os tratamentos congelador por 6 horas $(-10$ $\left.{ }^{\circ} \mathrm{C}\right)$, suco de laranja e a testemunha apresentaram resultados estatisticamente inferiores, quando comparados aos demais tratamentos (Quadro 2).

Corroborando com esta pesquisa, Silva et al. (2017), trabalhando com giberelina concluiu que as sementes de graviola submetidas aos tratamentos usando ácido giberélico (GA3) com imersão durante 96 horas, nas dosagens de a 0,5 e 4,0 mg. $\mathrm{L}^{-1}$, apresentaram crescimento vegetativo superior aos demais tratamentos físicos num período de até os $60 \mathrm{DAS}$.

Santos Filho (2007), estudando a superação de dormência de sementes de graviola, verificou que as concentrações de 740,75 e $582,95 \mu \mathrm{L} \mathrm{L}^{-1}$ de giberelina líquida promoveram melhor desenvolvimento inicial das plântulas, respectivamente, maior incremento estimado no comprimento de caule e raiz, utilizando substrato papel toalha, as médias superaram o tratamento controle, com valores de 90,19 e $85,35 \%$, respectivamente. Sauter e Kende (1992) afirmam que o maior crescimento da plântula, baseia-se na elongação das células do meristema intercalar, e que ao aumentar de tamanho promovem a divisão celular. Taiz e Zeiger (2013), relatam, que embora o crescimento do caule pode ser significativamente aumentado pela ação da giberelina, ela apresenta pouco efeito no crescimento da raiz.

Ao avaliar a massa verde foliar das plântulas foi observado que o tratamento com imersão em giberelina
$4.000 \mathrm{mg} . \mathrm{L}^{-1}$ apresentou maior valor de massa verde foliar, porém, estatisticamente superior apenas aos tratamentos água de coco, congelador $\left(-10^{\circ} \mathrm{C}\right)$ e $\mathrm{KCl} 5$ g.L $\mathrm{L}^{-1}$. Também na avaliação da MSF, o tratamento com imersão em giberelina $4.000 \mathrm{mg} . \mathrm{L}^{-1}$ apresentou maior valor, porém, estatisticamente superior apenas aos tratamentos congelador $\left(-10^{\circ} \mathrm{C}\right)$, gelo $(0$ $\left.{ }^{\circ} \mathrm{C}\right)$, geladeira $\left(10^{\circ} \mathrm{C}\right), \mathrm{NaCl} 9$ g.L ${ }^{-1}$ e $\mathrm{KCl} 5$ g.L.-1 e GA3 1000 mg.L.-1 (Quadro 3).

Quadro 3 - Produção de massa verde e seca em plântulas de graviola provenientes de sementes submetidas a diferentes tratamentos pré germinativos

\begin{tabular}{|c|c|c|c|c|}
\hline Tratamentos & MVF & MSF & MVR & MSR \\
\hline Testemunha & $1,0144 \mathrm{ab}$ & 0,189 abcd & $0,666 \mathrm{abc}$ & $0,087 \mathrm{bcd}$ \\
\hline $\begin{array}{l}\text { Geladeira (10 } \\
\left.{ }^{\circ} \mathrm{C}\right)\end{array}$ & $0,976 \mathrm{ab}$ & 0,169 cde & $0,717 \mathrm{a}$ & $0,095 \mathrm{ab}$ \\
\hline $\begin{array}{l}\text { Água com } \\
\text { gelo }\left(0^{\circ} \mathrm{C}\right)\end{array}$ & $0,925 \mathrm{ab}$ & $0,168 \mathrm{de}$ & $0,605 \mathrm{abc}$ & $0,079 \mathrm{~cd}$ \\
\hline $\begin{array}{l}\text { Congelador } \\
\left(-10^{\circ} \mathrm{C}\right)\end{array}$ & $0,866 \mathrm{~b}$ & $0,158 \mathrm{e}$ & $0,551 \mathrm{bc}$ & $0,077 \mathrm{~d}$ \\
\hline $\begin{array}{l}\text { GA3 } 1000 \\
\text { mg.L. }\end{array}$ & $0,940 \mathrm{ab}$ & $0,185 \mathrm{bcd}$ & $0,674 \mathrm{abc}$ & $0,096 \mathrm{ab}$ \\
\hline $\begin{array}{l}\text { GA3 } 2000 \\
\text { mg.L } L^{-1}\end{array}$ & $0,943 \mathrm{ab}$ & 0,189 abcd & $0,632 \mathrm{abc}$ & $0,096 \mathrm{ab}$ \\
\hline $\begin{array}{l}\text { GA3 } 3000 \\
\text { mg.L } L^{-1}\end{array}$ & $0,972 \mathrm{ab}$ & $0,203 \mathrm{ab}$ & $0,582 \mathrm{abc}$ & $0,093 \mathrm{ab}$ \\
\hline $\begin{array}{l}\text { GA3 } 4000 \\
\text { mg. } L^{-1}\end{array}$ & $1,083 \mathrm{a}$ & $0,208 \mathrm{a}$ & $0,701 \mathrm{ab}$ & $0,097 \mathrm{ab}$ \\
\hline Água de coco & $0,859 \mathrm{~b}$ & 0,187 abcd & $0,521 \mathrm{c}$ & $0,088 \mathrm{bcd}$ \\
\hline Suco laranja & $0,961 \mathrm{ab}$ & $0,191 \mathrm{abc}$ & $0,579 \mathrm{abc}$ & $0,090 \mathrm{abc}$ \\
\hline $\mathrm{NaCl} 9$ g.L $\mathrm{L}^{-1}$ & $0,925 \mathrm{ab}$ & 0,175 cde & $0,628 \mathrm{abc}$ & $0,096 \mathrm{ab}$ \\
\hline $\mathrm{KCl} 5$ g.L.-1 & $0,895 \mathrm{~b}$ & 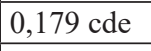 & $0,546 \mathrm{bc}$ & $0,100 \mathrm{a}$ \\
\hline $\begin{array}{l}\text { Água a } 100 \\
{ }^{\circ} \mathrm{C}\end{array}$ & 0 & 0 & 0 & 0 \\
\hline CV (\%) & 17,17 & 11,66 & 25,10 & 12,00 \\
\hline
\end{tabular}

Médias seguidas por uma mesma letra nas colunas não diferem estatisticamente pelo teste de Tukey a $5 \%$ de probabilidade. $\mathrm{MVF}=$ massa verde foliar $\left(\mathrm{mg} \mathrm{pl}^{-1}\right) ; \mathrm{MSF}=$ massa seca foliar $\left(\mathrm{mg} \mathrm{pl}^{-1}\right) ; \mathrm{MVR}=$ massa verde das raízes $\left(\mathrm{mg} \mathrm{pl}^{-1}\right)$; $\mathrm{MSR}=$ massa seca das raízes $\left(\mathrm{mg} \mathrm{pl}^{-1}\right) . \mathrm{CV}=$ coeficiente de variação.

Fonte: Dados da pesquisa

Na avaliação da massa verde radicular das plântulas, o tratamento Geladeira $\left(10{ }^{\circ} \mathrm{C}\right)$ apresentou o maior valor numérico, porém superior estatisticamente apenas aos tratamentos congelador $\left(-10^{\circ} \mathrm{C}\right)$, água de coco e $\mathrm{KCl} 5$ g.L $\mathrm{L}^{-1}$. Para a variável massa seca das raízes, o tratamento com $\mathrm{KCl}$ 5 g. $L^{-1}$ apresentou o melhor resultado, porém sem diferença estatística para os tratamentos Suco laranja, $\mathrm{NaCl} 9$ g.L $\mathrm{L}^{-1}$, Geladeira $\left(10^{\circ} \mathrm{C}\right)$ e os quatro tratamentos com giberelina (Quadro 3).

\section{Conclusão}

O tratamento com giberelina apresenta resultado positivo para a melhoria do estímulo da emergência e do desenvolvimento inicial das plântulas, sendo a dosagem de $4.000 \mathrm{mg} \mathrm{L}^{-1}$ de $\mathrm{GA}_{3}$ recomendada como tratamento de sementes de graviola.

O tratamento térmico em baixas temperaturas em sementes 
de graviola, apresenta-se ineficiente como estimulador da emergência e do desenvolvimento de plântulas de graviola, não sendo recomendado para esta espécie.

\section{Referências}

ALVARES, C.A. et al. Köppen's climate classification map for Brazil. Meteorol. Zeitschrift, v.22, n.6, p.711-728, 2013. doi: 10.1127/0941-2948/2013/0507

BRAGA SOBRINHO, R.; MESQUITA, A.L.M.; HAWERROTH, F.J. Manejo integrado de pragas na cultura da ata. Fortaleza: Embrapa Agroindústria Tropical, 2012.

BRAGA SOBRINHO, R. Produção integrada de anonáceas no Brasil. Rev. Bras. Fruticultura, v.36, p.102-107, 2014. doi: 10.1590/S0100-29452014000500012

GAJALAKSHMI, S.; VIJAYALAKSHMI, S.; DEVI RAJAESWARI, V. Phytochemical and pharmacological properties of Annona muricata: a review. Int. J. Pharm. Pharmaceutical Scie., v.4, n.2, 2012.

INCAPER. Planejamento e programação de ações para Santa Teresa. Programa de assistência técnica e extensão rural PROATER, Secretaria de Agricultura, 2011.

JOSÉ, A.C.; SILVA, E.A.; DAVIDE, A.C. Classificação fisiológica de sementes de cinco espécies arbóreas de mata ciliar quanto a tolerância à dessecação ao armazenamento. Rev. Bras. Sementes, v.29, n.2, p.171-178, 2007. doi: 10.1590/S010131222007000200023

KITAMURA, M.C.; LEMOS E.E.P. Enxertia precoce da gravioleira. Rev. Bras. Fruticul., v.26, p.186-188. 2004. doi: 10.1590/S0100-29452004000100050

LEMOS, E.E.P. A produção de anonáceas no Brasil. Rev. Bras. Fruticul. v.36, p.77-85. 2014. doi: 0.1590/S010029452014000500009

MANICA, I. Taxonomia, morfologia e anatomia. In: SÃO JOSÉ, A.R. et al. Anonáceas: produção e mercado. Vitória da Conquista: UESB, 1997. p.20-35.

MENEGAZZO, M.L.et al. Efeitos de métodos de superação de dormência em sementes de pinha (Annona squamosa L.). Agrarian, v.5, n.15, p.29-35, 2012.

OLIVEIRA L.C. et al. Efeito de diferentes substratos na germinação de sementes e formação inicial de plântulas de graviola. Rev. Verde Agroecol. Desenvol. Sustentável, v.4, p.90-
97, 2009.

PENG, J.; HARBERD, N.P. The role of ga-mediated signalling in the control of seed germination. Current Opinion in Plant Biology, v.5, n.5, p.376-381. 2002.

PIMENTA, A.C. et al. Giberelina na superação de dormência de sementes de araticunzeiro (Annona crassiflora MART. Annonaceae). Global Scie. Technol., v.12, n.2, p.79-86, 2019.

PINTO, A.C.Q. Influência de hormônio sobre o poder germinativo de sementes de graviola. In: CONGRESSO BRASILEIRO DE FRUTICULTURA, 3., 1975, Rio de Janeiro. Anais...Rio de Janeiro: Sociedade Brasileira de Fruticultura, p.415-420, 1976.

SAMARAO, S.S. et al. Desempenho de mudas de gravioleira inoculadas com fungos micorrízicos arbusculares em solo nãoesterilizado, com diferentes doses de fósforo. Acta Scientiarum Agronomy, v.33, n.1, p.81-88, 2011. doi: 10.4025/actasciagron. v33i1.5427.

SANTOS FILHO, A.L. Germinação de sementes, estaquia e enxertia em gravioleira (Annona muricata L.). Cruz das Almas: Universidade Federal da Bahia, 2007.

SAO JOSE, A.R. et al. Atualidades e perspectivas das Anonáceas no mundo. Rev. Bras. Fruticultura. v.36, p.86-93. 2014. doi: 10.1590/S0100-29452014000500010.

SAUTER, M.; KENDE, H. Gibberellin-induced growth and regulation of the cell division cycle in deepwater rice. Planta. v.188, p.362-368, 1992.

SILVA, J. G.; OLIVEIRA, O.H.; NOBRE, R.G. Produção de mudas de gravioleira sob métodos de superação de dormência de sementes e doses de esterco. Rev. Verde Agroecol. Desenvol. Sustentável., v.12, n.2, p.187-191, 2017. doi: 10.18378/rvads. v12i2.4649

STENZEL, N.M.C.; MURATA, I.M.; NEVES, C. Superação da dormência em sementes de atemóia e fruta-do-conde. Rev. Bras. Fruticultura, v.25, n.2, p.305-308, 2003. doi: 10.1590/S010029452003000200031

TAIZ, L.; ZEIGER, E. Fisiologia e desenvolvimento vegetal. Porto Alegre: Artmed, 2013.

VIEIRA, A.R. et al. Marcador isoenzimático de dormência em sementes de arroz. Rev. Bras. Sementes, v.30, n.1, p. 81-89, 2008. doi: 10.1590/S0101-31222008000100011

WATANABE, H.S. et al. Perfil de comercialização das anonáceas nas ceasas brasileiras. Rev. Bras. Fruticultura, v.36, p.65-70, 2014. doi: 10.1590/S0100-29452014000500007 